INTERNATIONAL JOURNAL OF

MULTIDISCIPLINARY STUDIES ON MANAGEMENT, BUSINESS, AND ECONOMY

\title{
THE ECONOMY AS AN APPROACH FOR THE UPGRADE OF HERITAGE DISTRICTS IN HISTORICAL CITIES

\author{
Hadeer AbdelShakour Ali ${ }^{1}$, Hossam Eldin Hassan Elborombaly ${ }^{2, *}$, Dina Maarouf Ahmed ${ }^{3}$ \\ ${ }^{1}$ Architecture Department, Ain Shams University, Cairo, Egypt \\ ${ }^{2}$ Architecture Department, Ain Shams University, Cairo, Egypt \\ ${ }^{3}$ Urban Planning Department, Ain Shams University, Cairo, Egypt
}

\begin{abstract}
There were many ways to preserve the urban heritage of historic districts in old cities, but at first, it was restoration for the monument only without regard to the urban context or the people of those areas. The following phase was a phase of urban upgrade projects, these projects objectives were preserving the monuments in the main axes like Al-Moez. Street, renewal of the infrastructure of the region and encouraging tourism, but there was little interest in achieving direct economic and investment returns from historic districts upgrade projects. Therefore, the idea of this research was to study and examine whether the projects of the historical districts upgrade may return direct economic returns to the people and residents of those areas and indirectly to sustain conservation and maintenance of the monuments.

Keywords

Economic Impact, Upgrade, Heritage Districts, Investment, Conservation Sustainability, Economic Returns, Tourism
\end{abstract}

\section{Introduction}

Importance of cultural heritage:

The cultural heritage of the people is an expression of the identity of this people, which must be preserved, and preserving it is a duty so that it does not perish and pass through the ages from one generation to another, as the identity of peoples is part of their future.

In order for the nation's heritage not to disappear and be part of its future, awareness must be spread among people to be aware of the value of heritage, and when a person knows the value of something he will care for and preserve it, then move to the stage of enjoying his heritage and preserving his identity, and thus thirsting for more and more understanding, and the following figure illustrates This meaning is in the so-called Heritage Cycle Diagram

Heritage areas:

They are the areas that have developed throughout history. These heritage areas are characterized by the presence of archaeological, historical or heritage buildings and are distinguished by the urban fabric. The uses of the buildings also represent a major part of the urban heritage in addition to the heritage buildings themselves, such as various types of trade, crafts or industries, which are an important part of the heritage considerations as well as social duty Nappy it. This is in accordance with the international conventions in the field of preserving the urban heritage.

Urban Heritage:

Urban heritage is all that a person has built in terms of urban communities and their buildings and their spaces and facilities that have value (urban, historical, scientific, cultural or national) dating back to ancient times and every building whose foundation was related to historical, religious, social, economic or events events. Security, political, or cultural, or it reflects the architectural styles and models or a civilization that has its own characteristics. Heritage is a receptacle for cultures and civilizations; It represents and preserves the essential characteristics of societies and nations that distinguish them from others, showing their heritage, and documenting their history.

Social and cultural values of urban heritage:

Cultural and Urban Value The value of the urban, cultural and urban heritage is evident in the fact that it witnessed the civilization and cultures of the parents and grandparents and the extent of their adaptation to the environment, which reflects the evolution of mankind through the ages. It testifies to urban experiences that nations have gone through, explaining urban values and identity. This is why the urban heritage is the reference for any nation looking to preserve its cultural identity.

Social value:

\footnotetext{
* Corresponding author: helborombaly@effatuniversity.edu.sa
} 
The development of urban heritage helps in increasing the awareness of communities through the establishment of programs and events at urban heritage sites, direct interaction with visitors, and the acquisition of some knowledge as well as training courses and new professions to contribute to development programs. All of this is in addition to supporting investment in urban heritage sites through some services and facilities that arise, thus directly contributing to community development and increasing per capita income. Preservation of the archaeological mini

Methods of preserving the heritage building

Preserving heritage buildings is through preserving them and their urban surroundings through an urban fabric that reflects the identity of the place, as the urban environment is an integral part of the building's history and its personality.

A group of charters such as the "Athens Charter", "the Charter of Florence", as well as the "Lahore Charter" have stipulated methods for preserving the heritage building and have been approved by UNESCO (UNEsco). The following is a brief overview of some of these methods:

Restoration:

It is the restoration of the building to its original state using specialized methods stipulated in international conventions, and restoration may be a structural restoration or an architectural restoration or they may be both together. The restoration requires extensive and comprehensive technical studies and its reference is to the historical documents of the building explaining its original condition.

Stopping the deterioration:

Determining the factors of deterioration of the building and its causes and stopping it in order to preserve its original condition. For example, one of those factors may be groundwater that causes the structural deterioration of the building or the inappropriate use of the archaeological site, which causes its deterioration.

Reconstruction:

It is that the heritage archaeological building or a large part of it be rebuilt in its original form using modern construction methods according to the conditions decided by heritage experts, and it is better to rebuild it in its original form if the documents explaining this are available.

Completion (Replacement and completion of components):

In the event of a collapse and loss of a part of the building, it shall be completed or rebuilt according to the specifications of the building with the same construction method, after protective studies so that no negative impact on the characteristics of the heritage building occurs.

Renovation:

It is a modernization of the building and supplying it with modern technologies such as air conditioning systems, fire alarm and fire control systems, the Internet and telephones, as well as water and sewage networks and updating them if they are present.

Consolidation:

It is a structural restoration of the building as a result of its deterioration due to the presence of cracks, cracks or collapses in part, and safety measures and precautions are taken while dealing with weak, structural deteriorating buildings by making strong internal and external arrays.

Rehabilitation:

It is the rehabilitation of the building, its modernization and development, and the introduction of some architectural and construction changes to match the building and suit its new function, for example adding some services in a manner and in a harmless manner that does not affect the characteristics of the heritage building, such as using some agencies as small hotels.

Adaptive Reuse:

It is a method used in dealing with historical and heritage buildings to preserve them and achieve societal and economic development, where a proposal for a new use is developed after thorough studies of the impact of this new use on the building to suit the nature of the building, the prevailing uses and the urban environment, and setting controls and standards for the application of the appropriate reuse project on the building.

Relocation of Monuments (1):

The antiquity acquires part of its value and history from its urban surroundings, and the Venice Charter stipulated that except in the case of inability to preserve the building in its place, and this was done in Egypt in the process of relocating the Temple of Philae as well as the Temple of Abu Simbel, for fear of being submerged. With the Nile water and the monuments drowned after the construction of the High Dam

Heritage value:

Heritage has many values and awareness and awareness of those values differs in one society from another category, it depends on the level of culture and education, there are economic and social factors that affect awareness of the value of heritage, and those who deal can be classified

The urban heritage preservation projects fall into three groups:

1. Those who benefit from conservation projects. 
2. Those who finance conservation projects.

3. Those who are interested in conservation projects.

The values of heritage buildings are evident from two sources:

The first: the fixed source, which is the building, and it is a source of direct income.

The second: an intangible source represented by the civilizational and cultural dimension, and it has no direct economic return.

The value is divided into two main economic types:

1- A value related to activities related to use.

2- A value related to activities not related to use.

- The economic importance of urban heritage preservation projects

1- Architectural heritage is a sustainable resource:

- Through the processes of preserving the urban heritage, investment resources are diversified, and heritage sites have multiple options for investors, which encourages investment.

- Existing buildings in heritage sites represent a sustainable resource that can be invested and reemployed in an appropriate manner instead of building new buildings to provide the value of new construction, which achieves a greater return on investment, as well as appropriate reuse to achieve the preservation of the building in a sustainable manner.

2- Providing job opportunities and reducing unemployment

- Rehabilitation projects for heritage areas and related projects that provide job opportunities for the people of these areas, and consequently the stability of the population living in these areas and increase their affiliation with the place, which contributes to the success of this type of projects.

3- Attracting private sector investments:

Investment by the private sector in projects to preserve the urban heritage is one of the important global investment areas.

4- Encouraging popular participation:

- Investing in heritage preservation projects with the participation of the people of the heritage areas helps in the success of the projects and the expansion of the extent of benefit, as the participation of the people has the greatest impact on the sustainability and continuity of these projects.

5- Preserving traditional crafts:

- Heritage areas linked to their history are a group of traditional crafts that must be preserved, and an essential part of the urban heritage preservation projects is to preserve the traditional crafts that have been associated with the inhabitants of the heritage areas, and they are inherited and legacy trades that must be preserved through their development and protection from extinction, as well as investment through them. By sponsoring and developing small workshops for those crafts and providing markets for their products.

Investing in urban heritage and financing methods:

- The archaeological buildings as well as the buildings of value are economic vessels and national wealth that can be exploited and increased in value through their economic investment.

- The use of archaeological buildings has an economic return, and this return depends on the extent to which the building's potential and its historical value are appropriately exploited, so exploiting the building in an inappropriate way may lead to a large profit and return at the beginning, but the end of it is failure because it leads to the loss of the building's original value and the loss of its historical value, which is the most important because the building The archaeologist is the legacy of the duty to preserve.

The success of reuse and employment projects can be measured by finding sources of income and financing that cover the cost of maintaining and maintaining the building.

- Before embarking on any of the reuse projects, a set of feasibility studies are carried out and the initial costs and returns of the project are calculated and how to achieve the maximum benefit from the building.

Programs and methods of investing in urban heritage:

Investment programs in urban heritage vary and take many forms, as follows:

1- State direct investments in archaeological areas for a limited period of time, through economic investment and the development of models to be successful and to become pilot models for investors to follow.

2- Investment partnerships that can be established to undertake the development of heritage areas.

3- Establishing the Heritage Areas Development Fund, and its goal is to find a source of financing that contributes to the development of society, by creating services that encourage investment in heritage areas, and the fund is financed by several bodies: a group of government sectors, as well as donations, private sector institutions and investors.

4- Adequate re-use of heritage buildings and employment may be in many uses, but before determining the type of use, adequate studies must be done, including a study of the suitability of the impact for the new job and the urban environment.

Employment of heritage buildings as a residential place: they can be permanent housing for their owners or invested by the private sector as heritage hotels. 
- Employment of heritage buildings as museums - Employment of heritage buildings as restaurants Employment of heritage buildings as exhibitions for plastic arts or centers for teaching traditional crafts and various arts.

Exploiting urban heritage sites as exhibitions for the products of traditional craftsmen

5- Paying attention to traditional crafts and their owners and providing them with small loans and markets to display their products and make them an attraction for tourists and those interested in those crafts and their products.

6- Programs to stimulate and support tourism in heritage areas through various media and study them by specialists in propaganda and media.

7- Exploiting open spaces within the urban fabric and investing them in cultural activities in a way that does not cause visual distortion or any negative impact on the buildings in the heritage area.

8- Establishing service and commercial centers and visitor centers that serve tourists and every visitor to the region, and offering them to the private sector to operate them in accordance with the criteria set by specialists in investment in urban heritage. buildings.

9- Developing the old markets and investing them in a manner appropriate to the nature of the heritage

10- Economic feasibility studies for investments in heritage areas before starting any investments and seeking assistance from specialists in this field.

11- Allocating part of the investment returns for the maintenance of heritage buildings and public squares to achieve the sustainability of urban heritage promotion projects.

Results:

1- Encouraging the private sector to invest in urban heritage achieves satisfactory economic returns for all parties involved in the process of preservation and upgrading (whether the investor himself, the people or the government).

2- Tourism investment in the development of heritage areas cannot be overlooked, which has economic, social and cultural returns.

3- Programs and methods of investing in the urban heritage.

Conclusion:

The process of preserving the antiquity itself, keeping it in good condition and reusing it in a manner appropriate to its nature and characteristics (such as reusing a heritage agency for a tourist hotel) achieves - in addition to the economic return - other valuable returns such as: the cultural return from the history of the antiquity itself and the extent of its distinguished architectural and artistic value as well as the development process. The community of the people of those heritage areas is like the continuation of preserving traditional crafts and employing not a few of them in various development fields.

\section{References}

1 - البرمبلى حا. (ابريل 2015). الأساليب والأسس العلمية الجدوى الاقتصادية للحفاظ على التراث العمراني والمعماري للمناطق التاريخية.

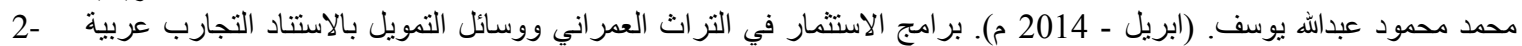

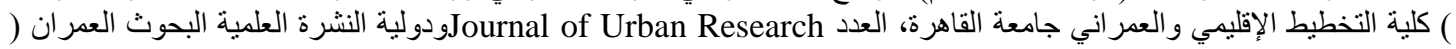

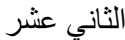

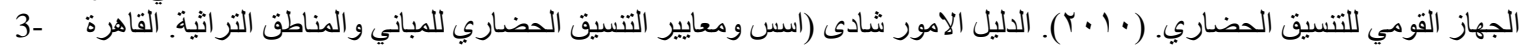

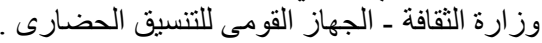

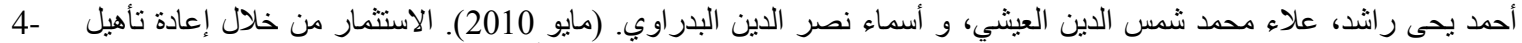
البيئات التزاثية المحلية (تحليل ورؤية مقترحة من منظور اقتصادي). المؤتمر الدولي الأول للتراث العمراني في الدول الإسلامية،

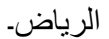

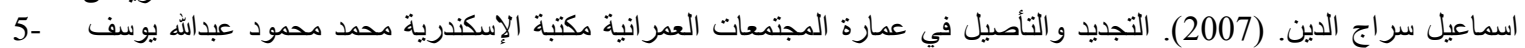

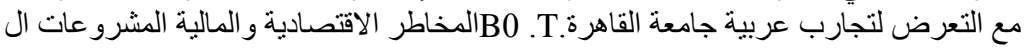

6- Petzet, M. (2009). International Principles of Preservation. Berlin: ICOMOS - published by hendrik Bäßler verlag.

7- Thurley, S) .summer 2005 (Into the future. Our stategy for 2005-2010.Conservation Bulletin [English Heritage, Issue 49.

8- ICOMOS. (2002) International Cultural Tourism Charter. Principles and Guidelines for Managing Tourism at Places of Cultural and Heritage Significance ICOMOS International Cultural Tourism Committee.

9- Ismail Serageldin) .May 1999 (Very Special Places: The Architecture and Economics of Intervening in Historic Cities Washington: The International Bank for Reconstruction and Development/THE WORLD BANK.

10- http://www.cultureindevelopment.nl/cultural_heritage/what_is_cultural_heritage 
THE ECONOMY AS AN APPROACH FOR THE UPGRADE OF HERITAGE DISTRICTS IN HISTORICAL CITIES

Received: January 15, 2019

Accepted: March 02, 2019 